\title{
Assemblage Characteristics and Habitat Specificity of Carabid Beetles in a Japanese Alpine-Subalpine Zone
}

\author{
Shinichi Hiramatsu ${ }^{1,2}$ and Nisikawa Usio $\mathbb{D}^{1,3}$ \\ ${ }^{1}$ Graduate School of Natural Science and Technology, Kanazawa University, Kanazawa 920-1192, Japan \\ ${ }^{2}$ Hakusan Nature Conservation Center, Hakusan 920-2132, Japan \\ ${ }^{3}$ Institute of Nature and Environmental Technology, Kanazawa University, Kanazawa 920-1192, Japan \\ Correspondence should be addressed to Nisikawa Usio; usio@se.kanazawa-u.ac.jp
}

Received 10 December 2017; Revised 12 February 2018; Accepted 28 February 2018; Published 3 April 2018

Academic Editor: G. Wilson Fernandes

Copyright (C) 2018 Shinichi Hiramatsu and Nisikawa Usio. This is an open access article distributed under the Creative Commons Attribution License, which permits unrestricted use, distribution, and reproduction in any medium, provided the original work is properly cited.

\begin{abstract}
In lowland areas of the world and high-altitude European mountains, the species compositions, body sizes, and wing forms of carabid beetles are known to change according to vegetation structures. However, little is known regarding the assemblage structure and habitat associations of carabid beetles in Japanese alpine-subalpine areas. We surveyed carabid beetles in four habitats (snow beds, alpine meadows, Pinus scrub, and fell-fields) in the alpine-subalpine zone on Mt. Hakusan, Japan. We surveyed carabid beetles six times between mid-July and late September. Nonmetric multidimensional scaling (NMDS) and analysis of similarities (ANOSIM) revealed three distinct carabid beetle assemblages in snow beds and alpine meadows, Pinus scrub, and fell-fields. The carabid beetle assemblages in the four habitats consisted predominantly of small and/or wingless species with differential spatiotemporal variability in abundance. Biota-environment (BIO-ENV) analyses showed that the percentage coverage by Pinus scrub, soil water content, and ground surface temperature were among the most significant variables affecting carabid beetle compositions. Given their small sizes and reduced wings, which are characteristic traits for limited mobility, and high-level habitat specificity, carabid beetles in the alpine-subalpine zone may serve as an important target group to monitor the impacts of global environmental change on mountain ecosystems.
\end{abstract}

\section{Introduction}

Mountain areas are generally characterized by harsh and unpredictable environments with low temperatures, strong winds, abundant snow, and changeable climates [1]. These characteristics are reflected in microclimatic differences in snow cover, temperature, soil water content, wind velocity, and substrate composition. Consequently, a great variety of habitats exists within small areas in mountainous areas, and the organisms therein are characterized by specific adaptations to the different microclimates [2]. In insects, small body size and brachyptery (reduced wings) are common morphological characteristics in high mountain areas $[1,3,4]$.

Coleoptera are among the most numerically dominant mountain insects in many parts of the world [1]. Carabid beetles (Carabidae) constitute more than half of the total species of Coleoptera on high mountains [1]. To date, numerous studies have shown that carabid beetle richness and/or assemblage composition change along altitudinal gradients [5-7] and/or with vegetation type [8-11]. For example, on Mt. Sobaeksan, Korea, carabid beetle assemblages were classified into low- and high-altitude groups [6]. In the Italian Alps, the species richness, activity level, and species traits (i.e., wing forms, geographical ranges, diets, and reproduction rhythms) of carabid beetles showed no or only weak correlation with altitude but were closely associated with habitat type [11]. Although there have been numerous studies on the habitat associations of carabid beetles in high-altitude mountain areas in Europe [12-14], such associations have not been reported from above the tree line in Japanese mountains.

The growing literature from lowland and mountain areas suggests that the abundance, species richness, and species composition of carabid beetles have been shown to change across habitats characterized by different vegetation structures, such as the presence of a tree canopy or forest type 


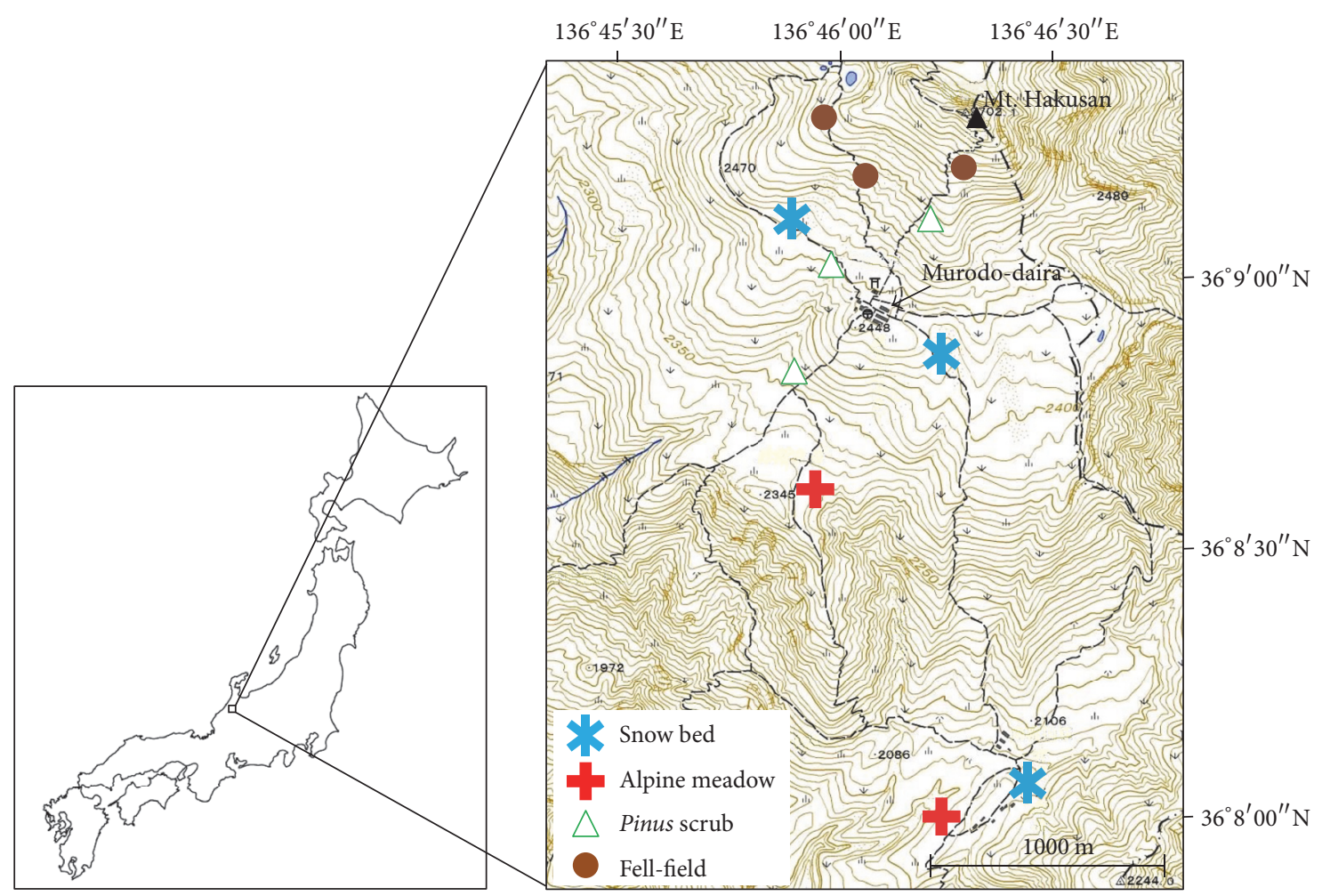

FIGURE 1: Maps showing the location of the study area and the 11 study sites encompassing four habitats in the alpine-subalpine zone on Mt. Hakusan in central Japan (Geospatial Information Authority scale of 1/50,000; Japan Topographic Map). Murodo-daira indicates the location of the meteorological station.

[15-17]. Furthermore, the body size and wing form of carabid beetles are known to change with habitat structure: stable habitats are generally represented by large and wingless species, whereas unstable or fragmented habitats are mainly represented by small and winged species [18-21]. In addition, carabid beetle richness and composition are also affected by microclimatic factors, such as soil water content and ground surface temperature [22-24]. Because of their close associations with vegetation structure undergoing natural and anthropogenic changes and the microclimatic variations associated with such changes [25-28], carabid beetles have been suggested to serve as useful bioindicators of environmental change $[28,29]$.

In recent years, global climate change has threatened mountain habitats and their organisms in many parts of the world. For example, in European mountains and the Andes, the distributions of vascular plants and carabid beetles have shifted toward higher altitudes [13, 30, 31]. In northern Japan, phenological mismatches are evident between the flowering seasons of alpine plants and the levels of activity of their bumblebee pollinators [32]. As soil moisture decreases and the annual growing period expands due to the recent acceleration in snowmelt time, Japanese alpine meadows have become invaded by dwarf shrubs and bamboos that, in turn, trigger desiccation of temporary wetland habitats $[33,34]$. Therefore, identifying habitat associations in a dominant insect group would be an important step toward understanding the consequences of global climate change in high mountain areas.
The objectives of this study were to investigate the assemblage characteristics and habitat associations of carabid beetles in the alpine-subalpine zone of a Japanese mountain. We tested two hypotheses. First, we tested whether the carabid beetles on a high mountain were associated with specific habitats, characterized by variation in vegetation structure and microclimate. Specifically, we hypothesized that the presence of Pinus scrub and changes in snowmelt along with associated microclimatic factors would determine the carabid beetle composition in the high mountain area. Second, we tested whether carabid species in the high mountain area exhibit specific body size or wing forms that are representative of harsh environments. Based on the literature $[1,3,4,14]$, we expected that body size would be small and wingless species would dominate the high mountain area numerically. We compared our results with studies performed in lowland areas on the same mountain. Our study is the first to document the habitat associations and morphological traits of carabid beetles from a high-altitude Japanese mountain.

\section{Materials and Methods}

2.1. Study Area. We conducted field surveys in the upper alpine-subalpine zone (altitude 2070-2600 m) on Mt. Hakusan in Ishikawa Prefecture, central Japan $\left(36^{\circ} 09^{\prime} \mathrm{N}, 136^{\circ} 46^{\prime} \mathrm{E}\right.$; Figure 1). The Mt. Hakusan area was designated a Biosphere Reserve by the UNESCO Man and the Biosphere program in 1980, with an extended area additionally registered in 2016 
[35]. The study sites were located in the core (protected) area of the Biosphere Reserve. According to the meteorological data at Murodo-daira station near the study sites (see Figure 1), the mean annual air temperature was $0^{\circ} \mathrm{C}$ in 2014 (range $-20^{\circ} \mathrm{C}$ to $20^{\circ} \mathrm{C}$ ) [36]; most of the study sites are covered with snow from November until June.

We selected two or three sites in each of four habitats for a total of 11 sites. To eliminate the influence of adjacent habitats, each site was selected from the center of the respective habitat type, with each site located more than $200 \mathrm{~m}$ from the others. We categorized the habitats with reference to a vegetation map of $1 / 25,000$ [37] and via field surveys. The four habitats consisted of snow beds, alpine meadows, Pinus scrub, and fell-fields (Figure 1). The snow beds are generally covered with snow until mid-July, after which the sites become dominated by dwarf scrub (Phyllodoce aleutica, Vaccinium uliginosum, and Geum pentapetalum). The alpine meadows are generally covered with snow until late June, and they become temporary wetlands in July. Later, these locations gradually dry out, and the sites subsequently become dominated by herbaceous plants (Carex blepharicarpa and Nephrophyllidium cristagalli). The Pinus scrub is covered by Pinus pumila about $2 \mathrm{~m}$ in height throughout the year. Fell-fields are exposed habitats that are very windy in winter; they support little vegetation other than sporadic patches of a dwarf shrub (Empetrum nigrum var. japonicum and $P$. pumila).

2.2. Carabid Beetle Sampling. We sampled carabid beetles six times on July 15 and 24, August 13 and 27, and September 11 and 23 in 2014 using baited pitfall traps made of polypropylene cups (diameter $9 \mathrm{~cm}$, depth $7 \mathrm{~cm}$ ). Sushi vinegar and powdered silkworm are baits commonly used in Japan to collect carabid beetles $[38,39]$. However, these two types of bait attract different carabid species [40]. We used both sushi vinegar and powdered silkworm to maximize the collecting efficiency of carabid beetles in an alpine area, where catches of carabid beetles are often small.

At each site, we placed 20 traps about $2 \mathrm{~m}$ apart along an arbitrarily designated $38 \mathrm{~m}$ line. We alternated sushi vinegar $(10 \mathrm{~mL} /$ trap $)$ and powdered silkworm $(10 \mathrm{~mL} /$ trap $)$ traps along the $38 \mathrm{~m}$ line. Therefore, there were 10 traps of each type at each site. We set up all of the traps from 8:00 to 12:00 of the same day. The following morning, 24 hours after the start of trapping, we emptied the traps and collected the carabid beetles. In the laboratory, we identified the carabid beetles to species using taxonomic keys [41-43]. For each site, we calculated the total number of carabid beetles captured in the 20 cups using the two different baits. We used digital calipers to measure body length (from the tip of the mandible to the posterior end of the elytra) of all collected individuals (excluding damaged samples) for nonabundant species ( $<40$ individuals/species). For abundant species ( $\geq 40$ individuals/species), we measured at least $65 \%$ of all collected individuals. Using data from equal numbers of males and females, we calculated the mean body length of each carabid beetle species. We classified all carabid beetles into one of three body size categories: small (body length $<10 \mathrm{~mm})$, medium $(10-20 \mathrm{~mm})$, and large $(>20 \mathrm{~mm})$ (based on previous studies [24, 44]). We also classified all carabid beetles as either macropterous (with fully developed hindwings), brachypterous (with very short or rudimentary hindwings), or apterous (with no hindwings) based on Jelaska and Durbešić [45]. Because no polymorphic species (sensu [45]) were identified in this study, we excluded this category from the wing form classification.

2.3. Environmental Variables. We selected six environmental variables that might affect the species richness, abundance, and assemblage composition of carabid beetles on Mt. Hakusan: soil water content, mean substrate size, ground surface temperature, diurnal temperature range, vegetation cover, and Pinus cover.

Using a portable soil water sensor (TDR-341F; Fujiwara Scientific Company, Tsukuba, Japan), we measured soil water content by inserting the probe to $5 \mathrm{~cm}$ depth from the soil surface. At each site, we arbitrarily took 10 readings to determine the mean soil water content. Subsequently, we placed two parallel $5 \mathrm{~m}$ tape measures horizontally ( $5 \mathrm{~m}$ apart) along the slope near the center of each site. We divided each $5 \mathrm{~m}$ line into 10 equidistant points. We used a ruler to determine the mean substrate size at 20 locations at each site. Prior to starting the first carabid beetle sampling, we placed a data logger (HOBO TidbiT v2; Onset Computer, Bourne, MA, USA) at the center of each site. Based on hourly temperature data collected from 13:00 to 12:00 the following day, we calculated the mean ground surface temperature and diurnal temperature range of the ground surface (the difference between the maximum and minimum temperatures). We visually estimated the percentage coverage of all vegetation and Pinus pumila based on two $5 \mathrm{~m}^{2}$ quadrats (10 $\mathrm{m}$ apart) that were placed near the center of each site.

At each sampling session, we measured soil water content, mean ground surface temperature, the temperature range, and the percentage coverage by vegetation. We recorded mean substrate size and percentage coverage by Pinus scrub only once (at the beginning of the study), because these parameters were expected to change little during the study period.

2.4. Data Analyses. We used factorial repeated measures analysis of variance (ANOVA) or one-way ANOVA to explore differences in six environmental variables (soil water content, mean substrate size, ground surface temperature, diurnal temperature range, vegetation cover, and Pinus cover) among the four habitats. For diurnal temperature range and vegetation cover, we used the Box-Cox transformation to meet the normality assumption of the model residuals. For four environmental variables (soil water content, ground surface temperature, diurnal temperature range, and vegetation cover), we treated habitat and day as fixed factors and day as a repeated measure. We considered day to be a fixed factor because the choice of sampling day was arbitrary. Using Mauchly's test of sphericity, we checked the sphericity assumption of within-subject effects (day, habitat $\times$ day) for the four environmental variables; all environmental variables satisfied the sphericity assumption (all $P>0.15$ ). When we analyzed the mean substrate size, we used one-way ANOVA with habitat as a fixed factor, because the variable was 
measured only once. Because there was zero variance in some habitats, the difference in Pinus cover among the four habitats could not be tested using factorial ANOVA.

We used generalized linear model (GLM) analyses to identify differences in the total carabid beetle abundance and species richness among the four habitats. We treated habitat and day as fixed factors and day as a repeated measure. We used a negative binomial model (log link) for total carabid abundance and a Poisson model (log link) for species richness data. When a habitat effect or habitat $\times$ day interaction was statistically significant $(P<0.05)$, we applied the sequential Bonferroni correction to the $P$ values of post hoc pairwise tests.

To explore differences in species compositions among the four habitats, we subjected all daily data and the pooled data from the six samplings to nonmetric multidimensional scaling (NMDS). NMDS is an ordination technique that depicts the configuration of samples in a specified number of dimensions based on the dissimilarity matrix and iterative algorithm [46]. Unlike eigenvalue-eigenvector techniques, such as principal component analysis, NMDS makes few assumptions about the nature of the data. Therefore, NMDS is a preferred ordination technique in ecological studies, in which data often show nonnormal distribution or nonlinear relationships between samples. Prior to NMDS analyses, we transformed the abundance data using fourth-root transformations [46]. In addition, we added a dummy variable because the data contained values of zero [46]. We drew two-dimensional ordination diagrams using the Bray-Curtis dissimilarity index as the distance matrix between study sites. To visualize the habitat associations of carabid beetles in the high mountain area, we added vector plots of the carabid beetle species based on Mantel matrix correlations using the Pearson correlation coefficient $(R)$. For clarity, only carabid beetle species with $R \geq 0.6$ are shown in the 2D-NMDS plots. We then performed an analysis of similarities (ANOSIM) to explore the statistical significance of observed differences in species compositions among the four habitats. ANOSIM is a nonparametric permutation procedure that is applied to the rank similarity matrix (based on the Bray-Curtis dissimilarity index in our case) underlying the ordination of samples [46]. We set the number of permutations to 999 . As the statistical significance of post hoc pairwise ANOSIM tests can be biased by global testing, we used sample and pairwise statistics $(R)$ to examine dissimilarities in carabid beetle compositions between different pairs of habitats.

We used the biota-environment (BIO-ENV) analysis to identify environmental variables that best explained the carabid beetle compositions. The BIO-ENV analysis uses all available environmental variables to identify the combination that best explains patterns evident in the biological data. In the BIO-ENV procedure, correlations between the dissimilarity matrices of species (based on Bray-Curtis dissimilarity) and environmental variables (based on Euclidean distance) are calculated [46]. To calculate these correlations, we used $R$ (Mantel matrix correlations using the Pearson correlation coefficient). We included six environmental variables (soil water content, mean substrate size, ground surface temperature, diurnal temperature range, vegetation cover, and
Pinus cover) as predictors. Before the BIO-ENV analysis, we fourth-root transformed carabid beetle abundance data and standardized all environmental variables [46]. We set the number of randomizations to 999 to determine the combinations of environmental variables that best explained carabid beetle similarity or dissimilarity between sites.

We performed the repeated measures ANOVA and GLMs in SPSS ver. 21 (IBM, New York, USA) and the NMDS, ANOSIM, and BIO-ENV analyses in Primer ver. 7 (PRIMERE, Auckland, New Zealand).

\section{Results}

3.1. Differences in Environmental Variables among the Four Habitats. Of the six environmental variables, the soil water content, mean substrate size, diurnal temperature range, and percentage coverage by vegetation differed significantly among the four habitats (Habitat: all $P<0.05$; Figure 2; Table S1). ANOVA could not be performed for Pinus cover, but this variable also clearly differed among the four habitats. A significant habitat $\times$ day interaction was evident in the ground surface temperature of the four habitats, but no overall habitat effect was apparent; that is, the ground surface temperature differed among the four habitats on some days, but such differences were not consistently observed throughout the study period.

Overall, snow beds were characterized by relatively high soil water content, large mean substrate size, high mean ground surface temperature, large diurnal temperature range, and high percentage coverage by vegetation (especially on August 13 and thereafter (Figure 2; Table S1)). Alpine meadows were similar to snow beds but had higher soil water content, smaller mean substrate size, and lower diurnal temperature range. Pinus scrub areas were characterized by relatively low soil water content, small mean substrate size, low mean ground surface temperature, small diurnal temperature range, and extensive vegetation cover (dominated by Pinus scrub). Fell-fields were characterized by low soil water content, large mean substrate size, high mean ground surface temperature, high diurnal temperature range, and sparse vegetation cover.

3.2. Carabid Beetles. We collected 997 carabid beetles of 23 species (Table 1). All collected individuals were adults; no larvae were collected. The carabid beetle assemblages in the four habitats were numerically dominated by seven species: Bembidion sp., Platynus sp., Leptocarabus arboreus, Colpodes xestus, Pterostichus janoi, Platynus kitanoi, and Pterostichus honshuensis, which constituted $91 \%$ of the total carabid beetle abundance during the six sampling periods. The abundances of the remaining 16 carabid beetle species were very low, with only 1-16 individuals found during the six sampling periods. The number of species identified at each site on each sampling day was between two and seven (Table S2).

The mean body length of the 23 carabid beetle species ranged from $3.6 \mathrm{~mm}$ (Trechus sp.) to $28.1 \mathrm{~mm}$ (Leptocarabus procerulus) (Table 1). In all, 12 of the 23 collected species were $<10 \mathrm{~mm}$ in mean body length. Only two species of Leptocarabus were $>20 \mathrm{~mm}$ in mean body length. 


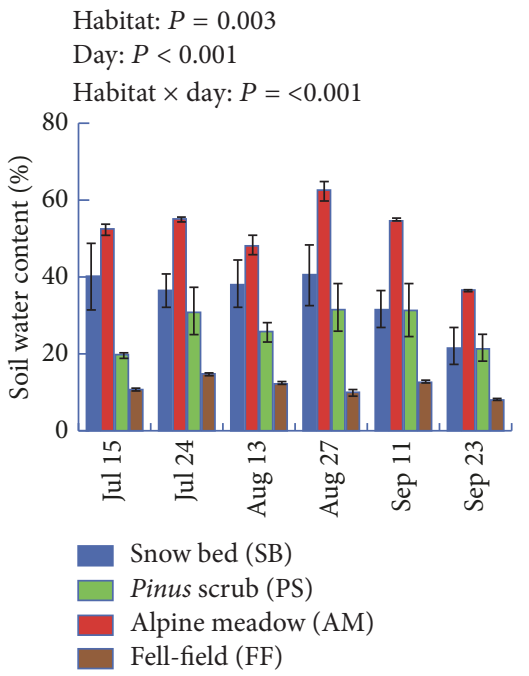

(a)

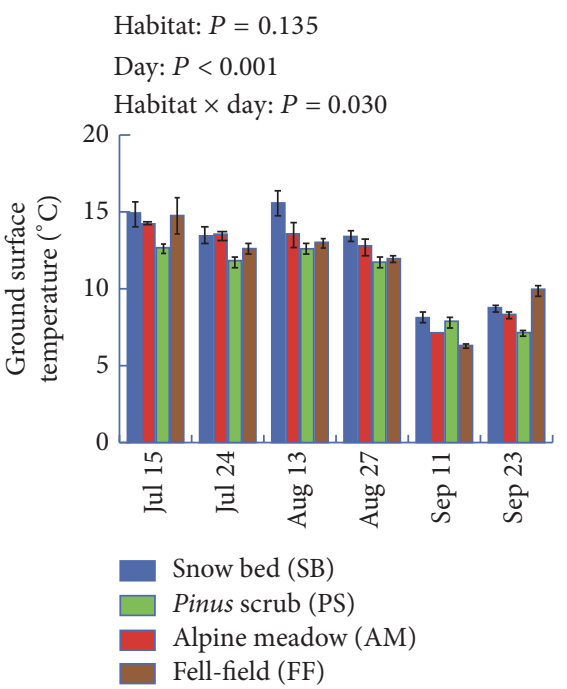

(b)

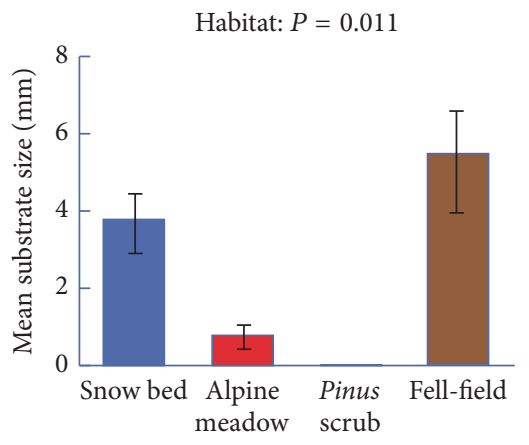

(e)

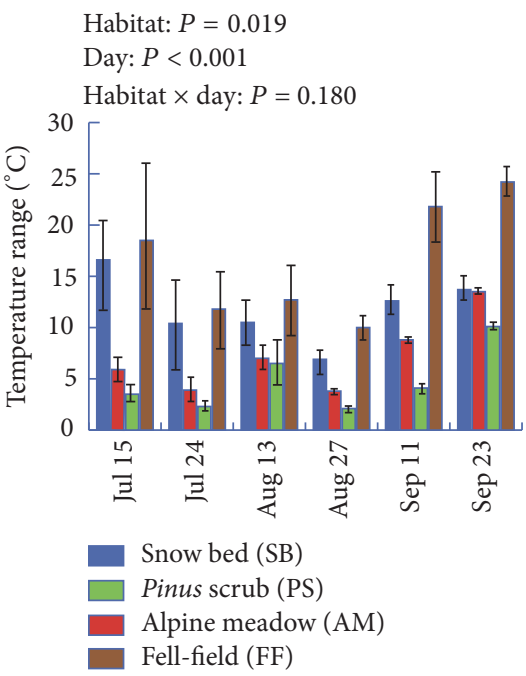

(c)

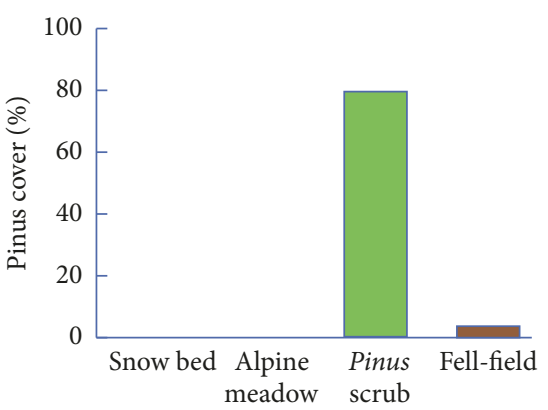

(f)

FIGURE 2: Soil water content (a), ground surface temperature (b), diurnal temperature range (c), vegetation cover (d), mean substrate size (e), and Pinus cover (f) in four habitats of the alpine-subalpine zone on Mt. Hakusan in central Japan. The $P$ values are based on the results of repeated measures ANOVA (soil water content, ground surface temperature, diurnal temperature range, and vegetation cover) and one-way ANOVA (mean substrate size) testing for differences in environmental variables among the four habitats. The difference in Pinus cover among the four habitats could not be tested using factorial ANOVA. Data are presented as means $\pm 1 \mathrm{SE}$.

Of the 23 carabid beetle species identified in the study, only four species (Bembidion fujiyamai, Diplous depressus, Platynus sp., and Harpalus fuliginosus) were macropterous, and the remaining 19 species were brachypterous or apterous (Table 1). All macropterous species were recorded from nonPinus scrub habitats.

GLM did not reveal a significant habitat $\times$ day interaction in the total carabid beetle abundance $\left(F_{15,14}=1.63, P=\right.$ 0.184; Figure 3(a)). However, a significant habitat effect was apparent for the total carabid beetle abundance $\left(F_{3,37}=3.58\right.$, $P=0.023)$. Subsequent post hoc tests revealed that the total carabid beetle abundance differed significantly between fellfields and Pinus scrub $(P=0.021)$ but not between the remaining habitat combinations (all $P>0.26$ ). By contrast, neither a habitat $\times$ day interaction $\left(F_{15,13}=0.69, P=0.757\right)$ nor a habitat effect $\left(F_{3,39}=0.66, P=0.583\right)$ was significant for carabid species richness (Figure 3(b)).

Total carabid beetle abundance was highest on July 15 , followed by July 24, and it declined thereafter (Figure 3(a)). The carabid beetles collected on July 15 and 24 constituted $82 \%$ of all carabid beetles collected in the study period. There were large spatial and temporal variations in carabid beetle abundance both among and within the four habitats. In snow beds and alpine meadows, carabid beetle abundance peaked on July 15 and declined dramatically after this date (Figure 3(a), Table S2). The rapid decline in total carabid beetle abundance in snow beds and alpine meadows from July 15 to August 13, in particular, was mainly due to two 
TABLE 1: Total and measured sample numbers, mean body lengths ( \pm SDs), size classes, and wing forms of carabid beetles in the alpinesubalpine zone on Mt. Hakusan in central Japan.

\begin{tabular}{|c|c|c|c|c|c|}
\hline Species & Total samples (number) & Measured samples (number) & Mean body length $\pm \mathrm{SD}(\mathrm{mm})$ & Size class & Wing form \\
\hline Leptocarabus arboreus & 102 & 80 & $22.2 \pm 0.88$ & $\mathrm{~L}$ & ap \\
\hline Leptocarabus procerulus & 2 & 2 & $28.1 \pm 0.00$ & $\mathrm{~L}$ & ap \\
\hline Leistus subaeneus & 9 & 8 & $8.7 \pm 0.08$ & $S$ & ap \\
\hline Nippononebria pusilla & 16 & 14 & $8.2 \pm 0.41$ & S & br \\
\hline Nebria sadona & 3 & 3 & $12.0 \pm 0.13$ & M & ap \\
\hline Nebria reflexa & 3 & 2 & $11.2 \pm 0.00$ & M & br \\
\hline Trechiama lewisi & 3 & 2 & $7.2 \pm 0.48$ & $\mathrm{~S}$ & ap \\
\hline Trechus sp. & 10 & 10 & $3.6 \pm 0.26$ & $S$ & ap \\
\hline Bembidion fujiyamai & 15 & 14 & $4.4 \pm 0.27$ & S & $\mathrm{ma}$ \\
\hline Bembidion sp. & 459 & 369 & $4.6 \pm 0.34$ & $\mathrm{~S}$ & br \\
\hline Diplous depressus & 1 & 1 & 12.3 & M & $\mathrm{ma}$ \\
\hline Apatrobus hasemiya & 2 & 2 & $8.3 \pm 0.00$ & $\mathrm{~S}$ & br \\
\hline Platynus kitanoi & 46 & 44 & $6.3 \pm 0.34$ & S & br \\
\hline Platynus sp. & 131 & 88 & $6.3 \pm 0.48$ & S & $\mathrm{ma}$ \\
\hline Colpodes xestus & 80 & 60 & $10.3 \pm 0.53$ & M & ap \\
\hline Trigonognatha aurescens & 10 & 10 & $16.8 \pm 0.20$ & M & ap \\
\hline Pterostichus honshuensis & 45 & 36 & $10.8 \pm 0.46$ & M & br \\
\hline Pterostichus janoi & 47 & 40 & $11.6 \pm 0.44$ & M & ap \\
\hline Pristosia aeneola & 1 & 1 & 12.8 & M & ap \\
\hline Synuchus takeuchii & 7 & 7 & $8.1 \pm 0.32$ & $\mathrm{~S}$ & ap \\
\hline Trephionus kinoshitai & 2 & 2 & $8.9 \pm 0.33$ & S & ap \\
\hline Harpalus fuliginosus & 2 & 2 & $9.2 \pm 0.15$ & $\mathrm{~S}$ & $\mathrm{ma}$ \\
\hline Trichotichnus sp. & 1 & 1 & 10.4 & M & br \\
\hline
\end{tabular}

S, <10 mm; M, 10-20 mm; L, >20 mm; ma, macropterous; br, brachypterous; ap, apterous.

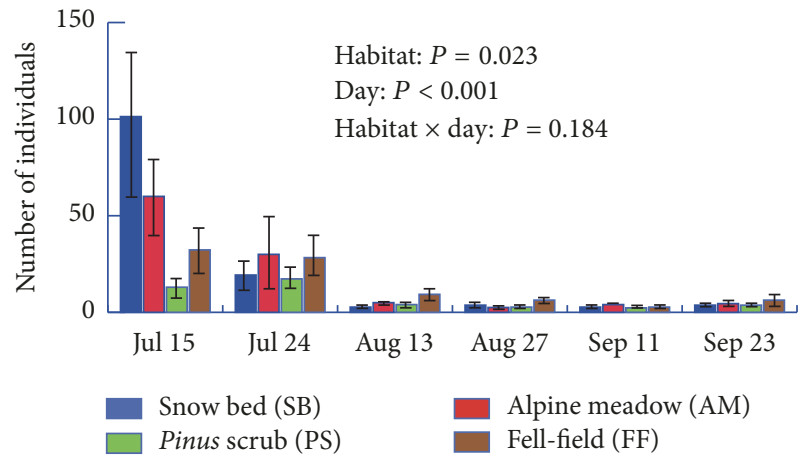

(a)

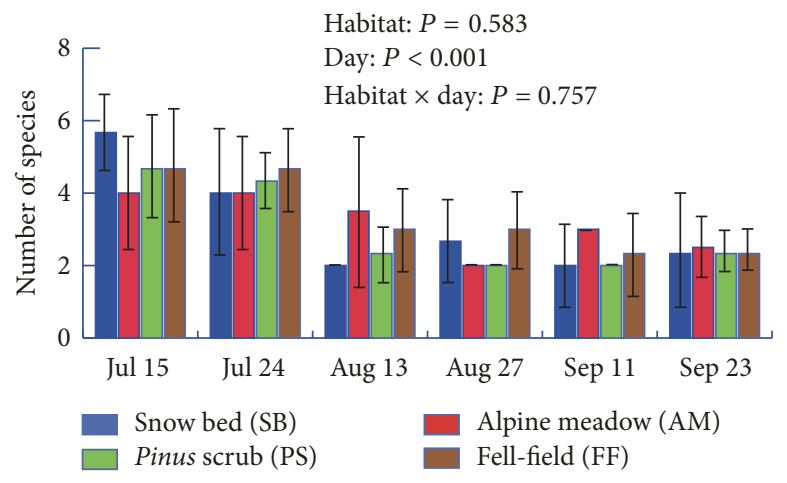

(b)

FIgURE 3: Total abundance (a) and species richness (b) of carabid beetles in the four habitats of the alpine-subalpine zone on Mt. Hakusan. $P$ values for the effects of habitat, day, and habitat $\times$ day interaction are based on negative binomial (for total abundance) and Poisson (for species richness) generalized linear models (GLMs). Data are presented as means $\pm 1 \mathrm{SE}$.

dominant species (Bembidion sp. and Platynus sp.), which together constituted approximately $90 \%$ of total carabid beetle abundance on the respective days in each habitat (Table S2). Likewise, in fell-fields, total carabid beetle abundance decreased from July 24 to August 13 with less temporal variation. Conversely, carabid beetle abundance in Pinus scrub showed less variation over time during the same summer period.
ANOSIM analyses revealed significant differences in carabid beetle compositions among the four habitats on July 15 and 24, August 13, and September 23 (significance levels $<5.0 \%$ ), while marginally significant differences were evident on August 27 and September 11 (significance levels 5.0-6.6\%) (Table 2). Post hoc pairwise ANOSIM analyses revealed that the carabid beetle compositions on July 15 and 24 differed among snow beds, alpine meadows, Pinus scrub, 
TABLE 2: Global test data and pairwise statistics derived by one-way analyses of similarities (ANOSIM) that explored differences in carabid beetle assemblages among the four habitats (six sampling dates) on Mt. Hakusan. All data were fourth-root transformed prior to ANOSIM analyses. $R$ denotes the Pearson correlation coefficient. The symbol "-" indicates that the pairwise test was not performed because the result of the global test was not significant $(\geq 5 \%)$.

\begin{tabular}{|c|c|c|c|c|c|c|c|c|}
\hline \multirow{2}{*}{ Sampling day } & \multicolumn{2}{|c|}{ Global test } & \multicolumn{6}{|c|}{ Pairwise statistic $(R)$} \\
\hline & Sample statistic $(R)$ & Significance level (\%) & SB \& AM & SB \& PS & SB \& FF & AM \& PS & $\mathrm{AM} \& \mathrm{FF}$ & PS \& FF \\
\hline July 15 & 0.764 & 0.2 & -0.250 & 1.000 & 0.815 & 1.000 & 1.000 & 0.778 \\
\hline July 24 & 0.929 & 0.1 & 0.167 & 1.000 & 1.000 & 1.000 & 1.000 & 1.000 \\
\hline August 13 & 0.564 & 0.2 & 0.667 & 0.574 & 0.944 & 0.250 & 0.917 & 0.111 \\
\hline August 27 & 0.320 & 6.6 & - & - & - & - & - & - \\
\hline September 11 & 0.333 & 5.0 & - & - & - & - & - & - \\
\hline September 23 & 0.409 & 2.2 & -0.167 & 0.519 & -0.148 & 1.000 & 1.000 & 1.000 \\
\hline Entire period & 0.849 & 0.1 & -0.250 & 1.000 & 0.852 & 1.000 & 1.000 & 0.963 \\
\hline
\end{tabular}

SB, snow beds; AM, alpine meadows; PS, Pinus scrub; FF, fell-fields.

and fell-fields $(R \geq 0.778)$, but the differences between snow beds and alpine meadows were small on these dates $(R=-0.250$ to 0.167$)$. The $2 \mathrm{D}$-NMDS ordination diagrams showed that, on July 15, the snow beds-alpine meadows were represented by Bembidion sp., Trechiama lewisi, Pterostichus honshuensis, and Platynus sp.; the Pinus scrub was represented by Pterostichus janoi, Trigonognatha aurescens, $C$. xestus, and L. arboreus; and the fell-fields were represented by Nippononebria pusilla (Figure 4). On July 24, the carabid beetle assemblages in the four habitats were similar to those on July 15 except that the snow beds-alpine meadows were no longer represented by T. lewisi; the Pinus scrub was also represented by Leistus subaeneus and P. kitanoi, together with P. janoi, C. xestus, and L. arboreus; and the fell-fields were represented by Trechus sp. rather than N. pusilla. The carabid beetle compositions over the entire sampling period (i.e., the combined temporal data) reflected the compositions on the two days in July. On August 13, the differences in carabid beetle compositions between Pinus scrub and alpine meadows $(R=0.250)$ and fell-fields $(R=0.111)$ were less than those on July dates, whereas the difference between snow beds and alpine meadows had become relatively high $(R=$ 0.667). On September 23, the differences in carabid beetle compositions resembled those on the July dates, except that the degree of dissimilarity between snow beds and fell-fields was less $(R=-0.148)$. On both August 13 and September 23 , the representative carabid beetle compositions of the respective habitats (as revealed by 2D-NMDS ordination diagrams) were ambiguous, except that the Pinus scrub was represented by Leistus subaeneus, P. kitanoi, and P. janoi on September 23.

All carabid beetle size classes were found in all habitat types (see Figure 5(a)). However, the carabid beetle assemblages of snow beds and alpine meadows consisted predominantly of small (Bembidion sp. and Platynus sp.) and medium ( $P$. honshuensis) species; that of Pinus scrub consisted principally of medium (C. xestus and P. janoi) and large (L. arboreus) species; and that of fell-fields consisted of small (Bembidion sp.), medium (C. xestus), and large ( $L$. arboreus) species. Most representative carabid beetle species were brachypterous or apterous (see Figure 5(b)). The only exception was the macropterous Platynus sp., which was a numerically dominant member of the snow bed-alpine meadow assemblage.

BIO-ENV analyses revealed significant associations between carabid beetle compositions and six environmental variables on July 15 and 24, August 27, and September 23 (significance levels $<5 \%$; Table 3 ). There was no significant association between carabid beetle compositions and environmental variables on August 13 and September 11 (significance levels $>5 \%$ ). On July 15 , the combination of environmental variables that best explained the species compositions included soil water content and percentage coverage by Pinus scrub. These two variables or one of these variables was also the principal predictor explaining carabid species compositions in the top five models on July 15 . For July 24 , the best set of predictors of carabid beetle composition included soil water content, ground surface temperature, and percentage coverage by Pinus scrub. Combinations of two or more of these three predictors appeared in the top five models for July 24. On August 27, the best set of predictors included ground surface temperature, diurnal temperature range, and the percentage coverage by Pinus scrub. These three variables or combinations of two of these variables always appeared among the top five models explaining carabid beetle compositions for August 27. By contrast to July, soil water content was not included in the top five models for August 27. On September 23, the best set of predictors included the percentage coverage by Pinus scrub. This variable always appeared among the top five models explaining carabid beetle composition for September 23 . Overall, percentage coverage by Pinus scrub was consistently among the most important predictors of carabid beetle compositions on Mt. Hakusan, whereas soil water content was an important predictor early in summer after snowmelt, and ground surface temperature and/or diurnal temperature range were important predictors thereafter.

\section{Discussion}

4.1. Characteristics of Carabid Beetle Assemblages in the Alpine-Subalpine Zone of Mt. Hakusan. Our study showed that the carabid beetles on Mt. Hakusan could be generally classified into three distinct assemblages: those of snow 
TABLE 3: Biota-environment (BIO-ENV) analyses identifying the best five sets of environmental predictors explaining carabid beetle compositions on Mt. Hakusan. $R$ denotes the Pearson correlation coefficient.

\begin{tabular}{|c|c|c|c|c|c|c|c|c|}
\hline \multirow{3}{*}{ Rank } & \multicolumn{2}{|c|}{ July 15} & \multirow{2}{*}{\multicolumn{2}{|c|}{$\begin{array}{c}\text { July } 24 \\
\text { Significance level } 0.2 \%\end{array}$}} & \multirow{2}{*}{\multicolumn{2}{|c|}{$\begin{array}{c}\text { August } 27 \\
\text { Significance level } 0.2 \%\end{array}$}} & \multirow{2}{*}{\multicolumn{2}{|c|}{$\begin{array}{c}\text { September } 23 \\
\text { Significance level 2.7\% }\end{array}$}} \\
\hline & Sign & nce level 0.1\% & & & & & & \\
\hline & $R$ & $\begin{array}{c}\text { Variable } \\
\text { combinations }\end{array}$ & $R$ & $\begin{array}{c}\text { Variable } \\
\text { combinations }\end{array}$ & $R$ & $\begin{array}{c}\text { Variable } \\
\text { combinations }\end{array}$ & $R$ & $\begin{array}{c}\text { Variable } \\
\text { combinations }\end{array}$ \\
\hline 1 & 0.718 & $\begin{array}{l}\text { Water } \\
\text { Pinus }\end{array}$ & 0.726 & $\begin{array}{c}\text { Water } \\
\text { Temperature } \\
\text { Pinus } \\
\end{array}$ & 0.604 & $\begin{array}{c}\text { Temperature } \\
\text { Range } \\
\text { Pinus } \\
\end{array}$ & 0.541 & Pinus \\
\hline 2 & 0.680 & $\begin{array}{l}\text { Water } \\
\text { Vegetation } \\
\text { Pinus }\end{array}$ & 0.684 & $\begin{array}{l}\text { Water } \\
\text { Pinus }\end{array}$ & 0.566 & $\begin{array}{c}\text { Substrate } \\
\text { Temperature } \\
\text { Range } \\
\text { Pinus }\end{array}$ & 0.541 & $\begin{array}{l}\text { Substrate } \\
\text { Pinus }\end{array}$ \\
\hline 3 & 0.640 & $\begin{array}{l}\text { Water } \\
\text { Range } \\
\text { Pinus }\end{array}$ & 0.679 & $\begin{array}{c}\text { Water } \\
\text { Temperature } \\
\text { Vegetation } \\
\text { Pinus } \\
\end{array}$ & 0.553 & $\begin{array}{c}\text { Temperature } \\
\text { Range } \\
\text { Variable } \\
\text { Pinus } \\
\end{array}$ & 0.534 & $\begin{array}{c}\text { Water } \\
\text { Substrate } \\
\text { Pinus }\end{array}$ \\
\hline 4 & 0.621 & $\begin{array}{c}\text { Water } \\
\text { Temperature } \\
\text { Pinus }\end{array}$ & 0.675 & $\begin{array}{c}\text { Water } \\
\text { Substrate } \\
\text { Temperature } \\
\text { Pinus }\end{array}$ & 0.540 & $\begin{array}{l}\text { Temperature } \\
\text { Pinus }\end{array}$ & 0.506 & $\begin{array}{l}\text { Water } \\
\text { Pinus }\end{array}$ \\
\hline 5 & 0.616 & $\begin{array}{l}\text { Water } \\
\text { Range } \\
\text { Vegetation } \\
\text { Pinus }\end{array}$ & 0.661 & $\begin{array}{c}\text { Water } \\
\text { Temperature } \\
\text { Range } \\
\text { Pinus }\end{array}$ & 0.529 & $\begin{array}{c}\text { Substrate } \\
\text { Temperature } \\
\text { Range } \\
\text { Vegetation } \\
\text { Pinus }\end{array}$ & 0.466 & $\begin{array}{c}\text { Temperature } \\
\text { Pinus }\end{array}$ \\
\hline
\end{tabular}

Water, soil water content. Substrate, substrate size. Temperature, mean ground surface temperature. Range, diurnal temperature range. Pinus, percentage coverage of Pinus scrub. Vegetation, percentage coverage by vegetation.

beds and alpine meadows, Pinus scrub, and fell-fields. These carabid beetle assemblages were generally characterized by depauperate fauna, with only two to three species numerically dominating each habitat. Our findings were consistent with those of previous studies documenting low carabid beetle richness in various mountainous areas in Japan, the European Alps, and South America [7, 11, 47, 48]. In lowland Japan, carabid beetles often comprise more than 10 species at a single site during their active season [49-51]. For example, 13-36 species of carabid beetles have been consistently identified from all sites ranging from forests to meadows to farmland at the foot of Mt. Hakusan below the current study sites [5254].

In addition, the carabid beetle assemblages at our study sites consisted predominantly of small species and individuals. While small carabid beetle species $(<10 \mathrm{~mm}$ body length) constituted $52 \%$ of the total carabid beetle species in the present study, the percentage contributions of small carabid beetle species were shown to be less than $20 \%$ of the carabid beetle assemblages in lowland areas (altitude 140-680 m) including lawn, grassland, and forest at the foot of Mt. Hakusan below the current study sites [54] (Figure 5(a)). Even within the same carabid beetle species, the body size is known to decrease with increasing altitude. For example, Sota [55] found that the mean body length of $L$. procerulus and $L$. arboreus decreased with increasing altitude. Nevertheless, in places where strong disturbances occur, the body size of carabid beetles may be small regardless of altitude. The prevalence of small carabid beetles at high altitude or in sites stressed by strong disturbances is probably due to depauperate food availability in these areas $[18,19$, 56, 57]. In fact, as the isolation or fragmentation of forests progresses, the proportions of small carabid beetle species have been shown to increase [45]. Therefore, small body size is a characteristic of carabid beetles that inhabit severe environments.

As reported in studies of alpine carabid beetles in Europe $[11,12,14]$, there was a large proportion of short-winged carabid beetles at our study site. Although less than $30 \%$ of the carabid beetle species were brachypterous or apterous and are incapable of flying in the lowland areas (altitude $140-680 \mathrm{~m}$ ) of Mt. Hakusan [54], 83\% (19 of 23 species) were brachypterous or apterous in our study (Figure 5(b)). The growing literature from lowland areas suggests that stable habitats, such as large forested areas, are generally represented by brachypterous or apterous carabid beetle species [21, 44, $45,57]$, whereas fragmented habitats, such as small patches of forest following deforestation, are generally represented by macropterous carabid species $[45,57,58]$. Herbaceous vegetation in high-altitude areas is usually in a stable, climax condition [59]; therefore, the carabid beetles living there may not need to move long distances. Alternatively, developing and maintaining full wings and flight muscles is energy intensive [3]. In harsh alpine-subalpine environments, carabid species may invest energy in survival rather than wingdevelopment.

Unlike the European Alps or Apennines, where the percentages of endemic carabid beetles are high [60], we 

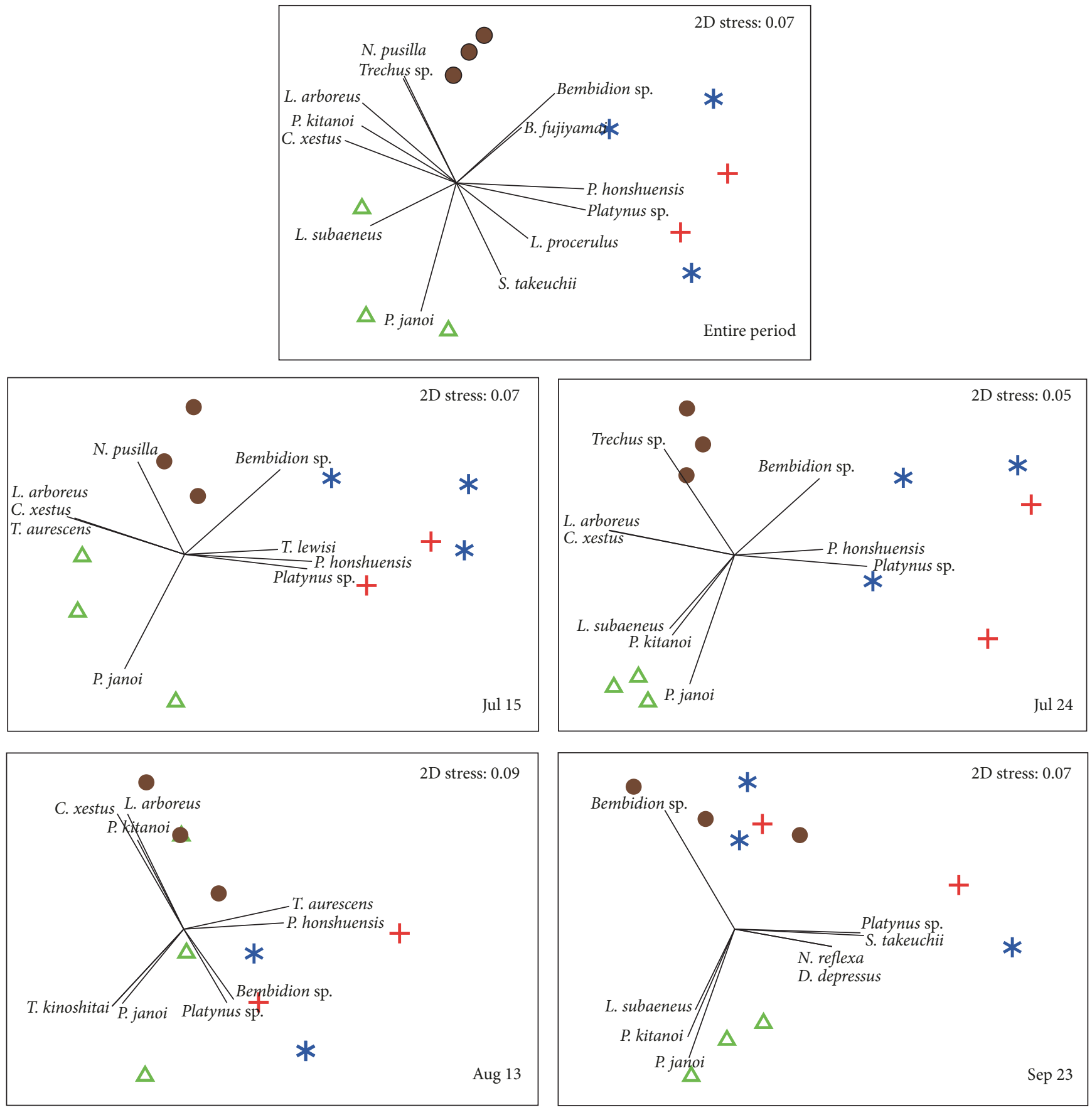

Habitat

Habitat
* Snow bed
$\triangle$ Pinus scrub
Fell-field
* Snow bed
+ Alpine meadow
$\Delta$ Pinus scrub
Fell-field
+ Alpine meadow

FIGURE 4: Nonmetric multidimensional scaling (NMDS) ordinations based on the abundance of carabid beetles on July 15 , July 24 , September 23 , and the entire period (pooled data) on Mt. Hakusan. Only carabid beetle species with a Pearson correlation coefficient $\geq 0.6$ are shown in the graphs. Vectors indicate the species that contributed significantly to discriminate the carabid beetle assemblages among the four habitats, with long vectors indicating the species with high contributions. The $2 \mathrm{D}$ stress indicates the model fit. 


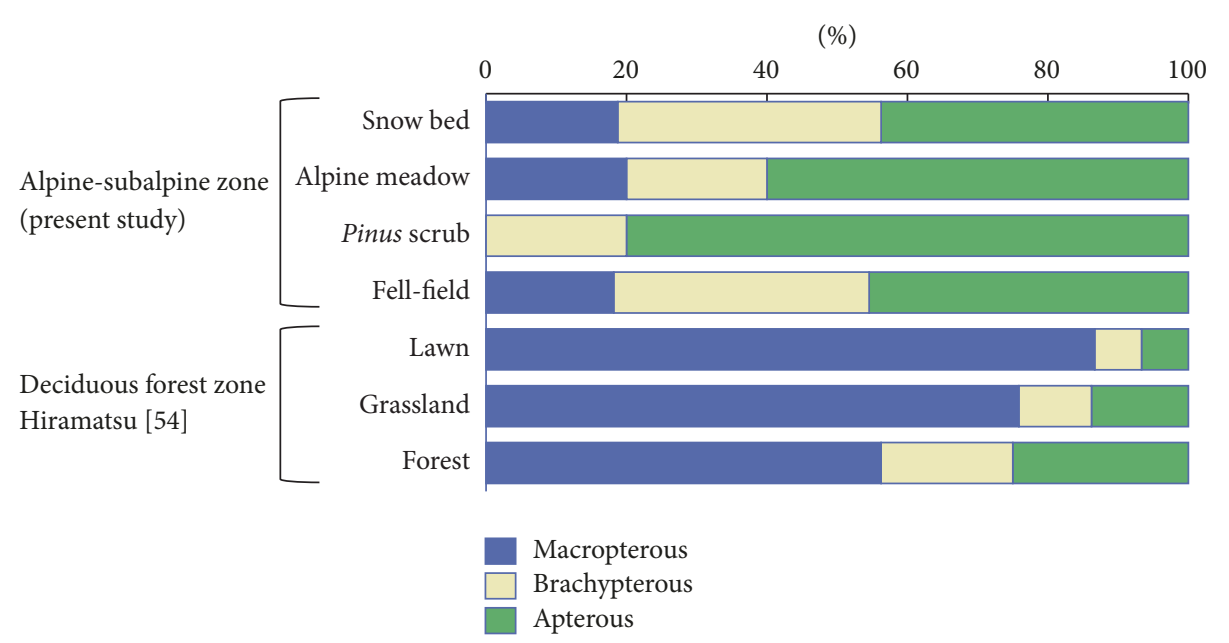

(a)

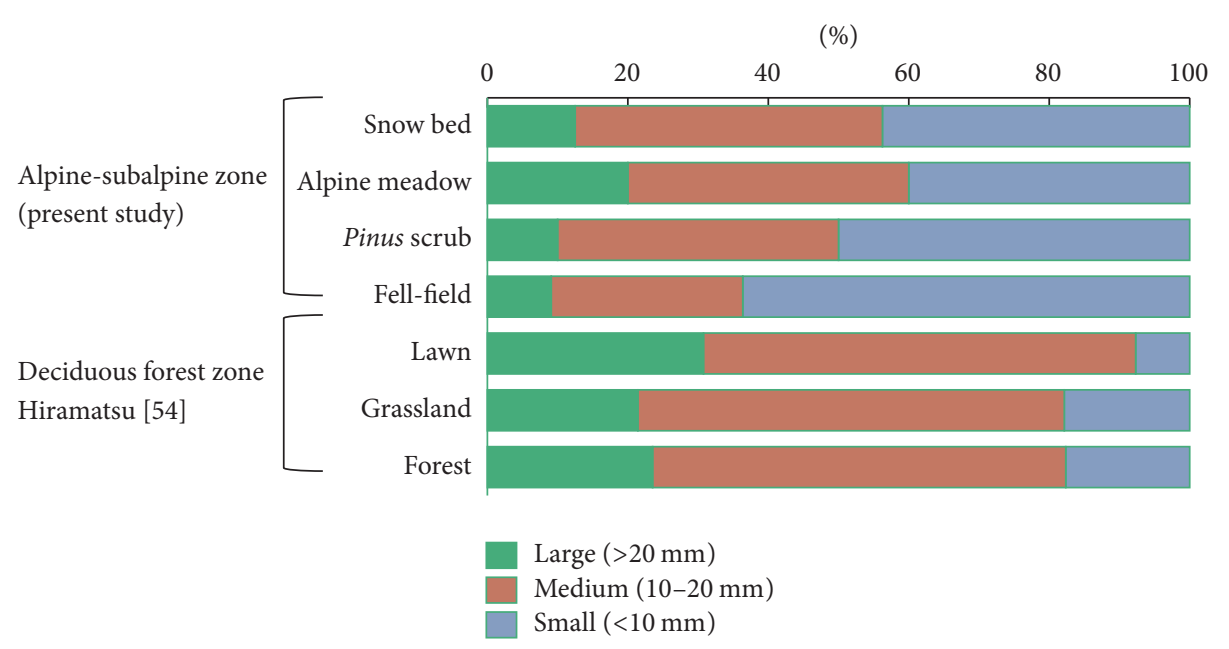

(b)

FIGURE 5: The percentage contributions of (a) small $(<10 \mathrm{~mm})$, medium $(10-20 \mathrm{~mm})$, and large $(>20 \mathrm{~mm})$ carabid beetles and $(\mathrm{b})$ macropterous, apterous, and brachypterous wing forms in the four habitats of the alpine-subalpine zone (altitude 2070-2600 $\mathrm{m}$ ) and three habitats in the deciduous forest zone (altitude 140-680 m) on Mt. Hakusan. The data for the deciduous forest zone are based on Hiramatsu [54].

did not find any endemic carabid species in the alpinesubalpine zone on Mt. Hakusan; some carabid species are common in other alpine areas of central Japan. Similarly, no endemic vascular plants have been reported from Mt. Hakusan. The lack of endemic species on Mt. Hakusan is probably due to the new geographical background of this area. Mt. Hakusan is a volcano that formed 30,000 to 40,000 years ago (Late Pleistocene) [61]. By contrast, the European Alps were formed between 66 and 150 million years ago (Cretaceous period) [62]. Nevertheless, there are signs that endemic carabid species are evolving on Mt. Hakusan. For, example, L. arboreus, which is a representative carabid species in many habitats on Mt. Hakusan, is endemic at the subspecies level on Mt. Hakusan and neighboring mountains in central Japan [41].

The carabid beetle fauna in the high mountain areas of Mt. Hakusan was more similar to that of the Japanese Alps than to that at the foot of the mountain. Between 14 and 15 carabid beetle species were previously recorded in studies conducted above $2000 \mathrm{~m}$ altitude in the Southern and Northern Japanese Alps [5, 63]. Of these, seven carabid beetles, C. exilis (synonym of L. arboreus), N. pusilla, Nebria sadona, T. aurescens, P. janoi, Pristosia aeneola, and Agonum kitanoi (synonym of $P$. kitanoi) from the Northern Japanese Alps, and four carabid beetles, L. arboreus, T. aurescens, Pterostichus oblongopunctatus (synonym of P. honshuensis), and $P$. aeneola from the Southern Japanese Alps, were commonly identified in our study. Mt. Hakusan is geographically isolated from the closest mountain in the Japanese Alps, which lies at a linear distance of over $50 \mathrm{~km}$. The 11 carabid beetle species commonly identified in high mountain areas on Mt. Hakusan and in the Japanese Alps have not been recorded from lowland areas $[45,46,64]$. During the ice age, many alpine plant species from northern areas colonized the mountains [65]. As the climate warmed, these plants were isolated as relics in areas at high elevation [65]. This scenario 
has also been reported for carabid beetles on high European mountains [59]. Likewise, alpine carabid beetles in Japan are probably distributed in isolated alpine habitats as relics.

Overall, carabid beetles in the high mountain areas of Mt. Hakusan were characterized by depauperate fauna with a small number of dominant species, small body size, wingless species, and isolated populations, with some species that are commonly distributed in high mountain ecosystems of the Japanese Alps.

\subsection{Effects of Habitat Type and Microclimate on Carabid Beetle} Assemblages. The total carabid beetle abundance in Pinus scrub was relatively constant during the study period. The Pinus scrub on Mt. Hakusan was associated with medium to large nonmacropterous species such as $L$. arboreus, $L$. subaeneus, T. aurescens, P. kitanoi, C. xestus, and P. janoi (Figure 4). Large body size and winglessness are typical of carabid beetles inhabiting stable habitats [66, 67]. In our study, large wingless species dominated the Pinus habitat, probably because Pinus scrub is a stable habitat in high mountain areas.

By contrast, the total carabid beetle abundance fluctuated markedly in the snow beds and alpine meadows (Figure 3(a)), probably because of the major environmental changes associated with summertime snowmelt. Although many carabid beetles in lowland areas have distinct breeding seasons in spring or autumn, those in high-elevation areas lack distinct breeding seasons [11]. With the rapid disappearance of snowmelt water, carabid beetles inhabiting snow beds and alpine meadows may need to breed rapidly just after snowmelt; consequently, the activity levels of all carabid beetles in snow beds and alpine meadows may increase simultaneously following snowmelt.

The snow beds and alpine meadows were also characterized by high soil water content (Table S1; Figure 2). In lowland areas, the soil water content is often among the most important factors influencing the assemblage compositions of carabid beetles [23, 68,69]. Representative carabid beetles of snow beds and alpine meadows were Bembidion sp., Platynus sp., and P. honshuensis, all of which are small to medium in size (Figure 5(a)). Because these three carabid beetle species have been mainly recorded from snow fields, alpine meadows, and/or river banks, but not from Pinus scrub on Mt. Hakusan [38, 70, 71], these species likely prefer moist alpine habitats. Moreover, Platynus sp. is macropterous and is thus expected to fly when dispersing. In lowland areas, many studies have found that small or macropterous carabid beetle species increased in number as the extent of disturbance rose $[44,66,67]$. Thus, snow beds and alpine meadows were probably represented by carabid beetles better adapted to inhabit unstable environments.

In addition to large temporal variation in the total carabid beetle abundance, intersite variation in the total carabid beetle abundance was also prominent in snow beds and alpine meadows between July 15 and 24 (Table S2). Hiramatsu [72] found that carabid beetle abundance on snow beds changed markedly with the distance from the remaining snow. Therefore, the large intersite variation in carabid beetle abundance in snow beds and alpine meadows observed in our study was probably caused by differential snowmelt stages and the associated differences in microclimatic factors.

Although fell-fields were represented by six species of carabid beetles, only two small or medium nonmacropterous species (N. pusilla and Trechus sp.) were unique to this habitat (Figure 4). Nippononebria pusilla and Trechus vicarius (synonym of Trechus sp.) have been previously documented from the alpine-upper subalpine zone of the Northern Japanese Alps [5]. Because N. pusilla and Trechus sp. have not been recorded from the non-fell-field habitats of Mt. Hakusan $[38,70,71]$, these two species might occur only in the high mountain fell-fields of central Japan. By contrast, the remaining four species also occurred in other habitats in the present study: Bembidion sp. in snow beds and alpine meadows, P. kitanoi and C. xestus in Pinus scrub, and $L$. arboreus in all habitats (Figure 4). Some small- to mediumsized carabid beetles (Bembidion sp., P. kitanoi, C. xestus, N. pusilla, and Trechus sp.) may use fell-fields as either temporary or permanent habitats. It is also possible that fell-fields serve as temporary habitats or dispersal corridors for mobile large carabid beetles (L. arboreus) that are predominantly found in other habitats.

Temperature also significantly affects carabid beetle compositions [73-75]. In our study, the mean ground surface temperature was an important predictor of carabid beetle compositions in three of the five best BIO-ENV models for July 24 and in all five best models for August 27, while the diurnal temperature range was an important predictor in the fifth best model for July 24 and in three of the best five best models for August 27 (Table 3). Therefore, the mean ground surface temperature was probably more significant in terms of carabid beetle compositions during the period shortly after snowmelt than was the diurnal temperature range. In late August, after the snow has melted completely, both the mean ground surface temperature and diurnal temperature range may become important in determining carabid beetle compositions.

\subsection{Carabid Beetles as an Important Target Group to Monitor} Ecological Effects of Global Warming on Mountain Ecosystems. Over the past few decades, signs of global warming have been reported in mountainous areas worldwide [76-78]. Of the various mountain habitats, snow beds and alpine meadows are expected to be severely impacted by global warming due to reduced winter snowfall, accelerated snowmelt, and lower ground moisture content after snowmelt [33, 79]. Furthermore, alpine meadows will be progressively invaded by Sasa spp. and $P$. pumila because of acceleration in the rate of desiccation [33, 80, 81]. Furthermore, if P. pumila invades snow beds and alpine meadows, the carabid beetles therein may be replaced by carabids representative of Pinus scrub, such as L. subaeneus, T. aurescens, P. kitanoi, C. xestus, and $P$. janoi. In this study, Platynus sp. and P. honshuensis were found almost exclusively in snow beds and alpine meadows; these species may be the first to disappear from the subalpine/alpine zone as global warming progresses. In addition, fell-fields constitute a critical mountain ecosystem that is found only in high mountain areas constantly exposed to strong winds. The minimum and maximum daily 
temperatures in high mountain areas have increased recently [82]. As global warming progresses, fell-fields may become hotter and dryer, and the interstitial spaces between rocks and underneath dwarf shrubs may no longer serve as refuges or temporary habitats for the carabid beetles that prefer such microhabitats. Consequently, carabid beetle species that are found exclusively in fell-fields, such as N. pusilla and Trechus sp., may disappear from high mountains.

\section{Conclusion}

In summary, the carabid beetle assemblages in the alpinesubalpine zone of Mt. Hakusan were generally characterized by small body size and reduced wings, with high habitat specificity. This study is the first to document the habitat associations and morphological traits of alpine carabid beetles on a Japanese mountain. The results conform to the general patterns reported from European mountains, which have a longer geological history and high carabid endemism [59].

Mountain areas are especially susceptible to global climate change [83, 84]. Given their high habitat specificity, carabid beetle assemblages in high mountain areas are expected to change dramatically in the face of global warming. Therefore, it will be important to monitor the abundance, species composition, and habitat associations of carabid beetles in the alpine-subalpine zone on Mt. Hakusan or elsewhere in the world.

\section{Disclosure}

Some of this research was a component of the MonitoringSite 1000 Alpine Zone Survey performed by the Biodiversity Center of Japan, Ministry of the Environment.

\section{Conflicts of Interest}

The authors declare no conflicts of interest associated with publication of this manuscript.

\section{Acknowledgments}

The authors acknowledge Chubu Regional Environmental Office, Hakusan Ranger Office for Nature Conservation, and Shirayama Hime Shrine for allowing them to perform field surveys in the study area.

\section{Supplementary Materials}

Table S1: summary of analyses of variance (ANOVA) of environmental variables among four habitats in the alpinesubalpine zone on Mt. Hakusan in central Japan. Repeated measures ANOVA was used to test differences in soil water content, ground surface temperature, diurnal temperature range, and vegetation cover among the four habitats. Oneway ANOVA was used to test the difference in mean substrate size among the four habitats. Table S2: numbers of individuals (per 20 baited pitfall traps) of carabid beetles collected at 11 sites in snow beds (SB), alpine meadows (AM), Pinus scrub (PS), and fell-fields (FF) in the alpine-subalpine zone on Mt.
Hakusan. The numbers following the abbreviations of each habitat are the site numbers. (Supplementary Materials)

\section{References}

[1] M. S. Mani, Ecology and Biogeography of High Altitude Insects, Junk Publ, Hague, Nederland, 1968.

[2] Y. Nakamura, "Alpine Vegetation," in Alpine Botany, T. Masuzawa, Ed., Kyoritsu Shuppan Co., Ltd., Tokyo, Japan, 2009.

[3] D. A. Roff, “The evolution of flightlessness in insects," Ecological Monographs, vol. 60, no. 4, pp. 389-421, 1990.

[4] L. Eweleit and K. Reinhold, "Body size and elevation: Do Bergmann's and Rensch's rule apply in the polytypic bushcricket Poecilimon veluchianus?” Ecological Entomology, vol. 39, no. 1, pp. 133-136, 2014.

[5] K. Kamimura, T. Nakane, and N. Koyama, "Seasonal and altitudinal distribution of the carabid beetles in the Mt. Jonen, the Japan Alps," The Scientific Reports of Kyoto Prefectural University. Natural Science and Living Science, vol. 3, no. 4, pp. 21-34, 1962 (Japanese).

[6] J.-K. Jung, S.-T. Kim, S.-Y. Lee, C.-G. Park, J.-K. Park, and J.H. Lee, "Community structure of ground beetles (Coleoptera: Carabidae) along an altitudinal gradient on Mt. Sobaeksan, Korea," Journal of Asia-Pacific Entomology, vol. 15, no. 3, pp. 1-7, 2012.

[7] S. A. Maveety, R. A. Browne, and T. L. Erwin, "Carabid beetle diversity and community composition as related to altitude and seasonality in Andean forests," Studies on Neotropical Fauna and Environment, vol. 48, no. 3, pp. 1-10, 2013.

[8] X.-D. Yu, T.-H. Luo, and H.-Z. Zhou, "Habitat associations and seasonal activity of carabid beetles (Coleoptera: Carabidae) in Dongling Mountain, North China," Entomologica Fennica, vol. 17, no. 2, pp. 174-183, 2006.

[9] E. Warren-Thomas, Y. Zou, L. Dong et al., "Ground beetle assemblages in Beijing's new mountain forests," Forest Ecology and Management, vol. 334, pp. 369-376, 2014.

[10] V. Gnetti, P. Bombi, A. Vigna Taglianti et al., "Temporal dynamic of a ground beetle community of Eastern Alps (Coleoptera Carabidae)," Bulletin of Insectology, vol. 68, no. 2, pp. 299-309, 2015.

[11] R. Pizzolotto, A. Albertini, M. Gobbi, and P. Brandmayr, "Habitat diversity analysis along an altitudinal sequence of alpine habitats: The carabid beetle assemblages as a study model," Periodicum biologorum, vol. 118, no. 3, pp. 241-254, 2016.

[12] M. Gobbi, B. Rossaro, A. Vater, F. De Bernardi, M. Pelfini, and P. Brandmayr, "Environmental features influencing Carabid beetle (Coleoptera) assemblages along a recently deglaciated area in the Alpine region," Ecological Entomology, vol. 32, no. 6, pp. 682-689, 2007.

[13] R. Pizzolotto, M. Gobbi, and P. Brandmayr, "Changes in ground beetle assemblages above and below the treeline of the Dolomites after almost 30 years (1980/2009)," Ecology and Evolution, vol. 4, no. 8, pp. 1284-1294, 2014.

[14] M. Gobbi, F. Ballarin, M. Brambilla et al., "Life in harsh environments: Carabid and spider trait types and functional diversity on a debris-covered glacier and along its foreland," Ecological Entomology, vol. 42, no. 6, pp. 838-848, 2017.

[15] M. Isaia, M. Paschetta, M. Gobbi, M. Zapparoli, A. Chiarle, and A. Vigna Taglianti, "Stand maturity affects positively grounddwelling arthropods in a protected beech forest," Annals of Forest Science, vol. 72, no. 4, pp. 415-424, 2015. 
[16] Y. Park, J. Kim, T. Jang, H. Chae, and Y. Takami, "Local climate mediates spatial and temporal variation in carabid beetle communities in three forests in Mount Odaesan, Korea," Ecological Entomology, vol. 42, no. 2, pp. 184-194, 2017.

[17] K. M. Staunton, A. Nakamura, C. J. Burwell, S. K. A. Robson, and S. E. Williams, "Elevational distribution of flightless ground beetles in the tropical rainforests of north-eastern Australia," PLoS ONE, vol. 11, no. 5, Article ID e0155826, 2016.

[18] S. Blake, G. N. Foster, M. D. Eyre, and M. L. Luff, "Effects of habitat type and grassland management practices on the body size distribution of carabid beetles," Pedobiologia, vol. 38 , no. 6 , pp. 502-512, 1994.

[19] G. L. Lövei and T. Magura, "Body size changes in ground beetle assemblages - A reanalysis of Braun et al. (2004)'s data," Ecological Entomology, vol. 31, no. 5, pp. 411-414, 2006.

[20] T. Magura, B. Tóthmérész, and G. L. Lövei, "Body size inequality of carabids along an urbanisation gradient," Basic and Applied Ecology, vol. 7, no. 5, pp. 472-482, 2006.

[21] M. Gobbi and D. Fontaneto, "Biodiversity of ground beetles (Coleoptera: Carabidae) in different habitats of the Italian Po lowland," Agriculture, Ecosystems \& Environment, vol. 127, no. 3-4, pp. 273-276, 2008.

[22] G. L. Lövei and K. D. Sunderland, "Ecology and behavior of ground beetles (Coleoptera: Carabidae)," Annual Review of Entomology, vol. 41, no. 1, pp. 231-256, 1996.

[23] J. Rainio and J. Niemelä, "Ground beetles (Coleoptera: Carabidae) as bioindicators," Biodiversity and Conservation, vol. 12, no. 3, pp. 487-506, 2003.

[24] J. Kaizuka and M. Iwasa, "Carabid beetles (Coleoptera: Carabidae) in coniferous plantations in Hokkaido, Japan: Esffects of tree species and environmental factors," Entomological Science, vol. 18, no. 2, pp. 245-253, 2015.

[25] J. Niemelä, D. J. Kotze, S. Venn et al., "Carabid beetle assemblages (Coleoptera, Carabidae) across urban-rural gradients : an international comparison," Landscape Ecology, vol. 17, no. 5, pp. 387-401, 2002.

[26] W. H. Heyborne, J. C. Miller, and G. L. Parsons, "Ground dwelling beetles and forest vegetation change over a 17-yearperiod, in western Oregon, USA," Forest Ecology and Management, vol. 179, no. 1-3, pp. 123-134, 2003.

[27] B. W. Warnaffe and P. Lebrum, "Effects of forest management on carabid beetles in Belgium: implications for biodiversity conservation," Biological Conservation, vol. 118, no. 2, pp. 219234, 2004.

[28] T. Magura, G. L. Lövei, and B. Tóthmérész, "Edge responses are different in edges under natural versus anthropogenic influence: a meta-analysis using ground beetles," Ecology and Evolution, vol. 7, no. 3, pp. 1009-1017, 2017.

[29] M. J. Koivula, "Useful model organisms, indicators, or both? Ground beetles (Coleoptera, Carabidae) reflecting environmental conditions," ZooKeys, vol. 100, pp. 287-317, 2011.

[30] H. Pauli, M. Gottfried, S. Dullinger et al., "Recent plant diversity changes on Europe's mountain summits," Science, vol. 336, no. 6079, pp. 353-355, 2012.

[31] P. Moret, M. D. L. Á. Aráuz, M. Gobbi, and Á. Barragán, "Climate warming effects in the tropical Andes: first evidence for upslope shifts of Carabidae (Coleoptera) in Ecuador," Agriculture, Ecosystems and Environment, vol. 9, no. 4, pp. 342350, 2016.

[32] G. Kudo, "Vulnerability of phenological synchrony between plants and pollinators in an alpine ecosystem," Ecological Research, vol. 29, no. 4, pp. 571-581, 2014.
[33] G. Kudo, Y. Amagai, B. Hoshino, and M. Kaneko, "Invasion of dwarf bamboo into alpine snow-meadows in northern Japan: Pattern of expansion and impact on species diversity," Ecology and Evolution, vol. 1, no. 1, pp. 85-96, 2011.

[34] Y. Nishikawa, M. Sumita, and S. Natsume, "Changes in flowering phenology of callianthemum miyabeanum in response to progressive warming at Mt. Apoi, Hokkaido, northern Japan," Japanese Journal of Conservation Ecology, vol. 14, no. 2, pp. 211222, 2009.

[35] S. Nakamura, S. Nakada, and T. Yamaguchi, "The management of Mount Hakusan Biosphere Reserve," in Mount Hakusan Biosphere Reserve, Y. Iida and S. Nakamura, Eds., pp. 24-29, United Nations University Institute for the Advanced Study of Sustainability Operating Unit, Kanazawa, Japan, 2016.

[36] Biodiversity Center of Japan, The Monitoring-Site 1000 alpine zone survey in 2014, Ministry of Environment, Fujiyoshida, Japan, 2015.

[37] I. Prefecture, Vegetation map of Mt. Hakusan Mountains (Ishikawa) and its survey report, Ishikawa Prefecture, Kanazawa, Japan, 1995.

[38] S. Hiramatsu, "The fauna and appearance time of the carabid beetle, in Mt. Hakusan, Ishikawa Prefecture, Japan," Annual Report of the Hakusan Nature Conservation Center, vol. 27, pp. 11-20, 2000 (Japanese).

[39] T. Maehara, "The efficiency of pitfall traps in relation to a density and activity of the carabid beetle, Carabus insulicola insulicola Chaudoir (Coleoptera: Carabidae), under controlled population density," Japanese Journal of Applied Entomology and Zoology, vol. 48, no. 2, pp. 115-121, 2004.

[40] S. Hiramatsu, "The appearance of the Coleoptera captured with pit-fall trap at the high place of Mt. Hakusan," Biogeography, vol. 4, no. 1, pp. 13-18, 2002.

[41] S. Ueno, R. Ishikawa, S. Kasahara, S. Morita, and K. Tanaka, "Carabidae," in The Coleoptera of Japan in color, S. Ueno, Ed., pp. 14-179, Hoikusha Publishing Co. Ltd., Osaka, Japan, 1985.

[42] A. Habu, Fauna Japonica, Carabidae: Harpalini (Insecta, Coleoptera), Keigaku Publishing Co. Ltd., Tokyo, Japan, 1973.

[43] A. Habu, Fauna Japonica, Carabidae: Platynini (Insecta, Coleoptera), Keigaku Publishing Co. Ltd., Tokyo, Japan, 1978.

[44] A. Fujita, K. Maeto, Y. Kagawa, and N. Ito, "Effects of forest fragmentation on species richness and composition of ground beetles (Coleoptera: Carabidae and Brachinidae) in urban landscapes," Entomological Science, vol. 11, no. 1, pp. 39-48, 2008.

[45] L. S. Jelaska and P. Durbešić, "Composition of the body size and wing form of carabid species (Coleoptera: Carabidae) between isolated and continuous forest habitats," Annales de la Société entomologique de France, vol. 45, no. 3, pp. 327-338, 2009.

[46] K. R. Clarke and R. N. Gorley, "PRIMER v7: User manual/ tutorial," PRIMER-E, Plymouth, UK, 2015.

[47] S. Fujiyama, M. Ohsawa, A. Sakai, O. Shibata, T. Sota, and Y. Yanagidaira, "Invertebrate, The form of organism and altitude," in The alpine biology, O. Shibata, Ed., pp. 135-146, Uchida Roukakuho Publishing Co. Ltd., Tokyo, Japan, 1996.

[48] P. Moret, "Altitudinal distribution, diversity and endemicity of carabidae (coleoptera) in the páramos of ecuadorian andes," Annales de la Société Entomologique de France, vol. 45, no. 4, pp. 500-510, 2009.

[49] K. Yahiro, "Species composition and seasonal abundance of ground beetles (Coleoptera) in a forest adjoining agroecosystems," Transactions of the Shikoku Entomological Society, vol. 19, no. 1, pp. 127-133, 1990. 
[50] M. Ishitani, T. Tsukamoto, K. Ikeda, K. Yamanaka, and K. Yano, "Faunal and biological studies of ground beetles (Coleoptera; Carabidae and Brachinidae)(1) Species composition on the banks of the same river," Japanese Journal of Entomology, vol. 65 , no. 4, pp. 704-720, 1997.

[51] R. Sato, M. Aizawa, K. Kubota, S. Shibuya, and T. Ohkubo, "Carabid Beetle Assemblages in Secondary Deciduous Broadleaved Forests with or without Litter Removal in Northern Kanto," Journal of the Japanese Forest Society, vol. 96, no. 3, pp. 141-145, 2014.

[52] S. Hiramatsu, "Distribution of ground beetles in some forest types at the foot of Mt. Hakusan," Annual Report of the Hakusan Nature Conservation Center, vol. 30, no. 1, pp. 17-24, 2003 (Japanese).

[53] S. Hiramatsu, "The species composition of the ground beetles (Carabidae and Brachinidae) assemblages in forests, meadows and farmlands at the foot of Mt. Hakusan," Annual Report of the Hakusan Nature Conservation Center, vol. 31, no. 1, pp. 55-65, 2004 (Japanese).

[54] S. Hiramatsu, "The appearance of the ground beetles (Carabidae and Brachinidae) in small habitats," Annual Report of the Hakusan Nature Conservation Center, vol. 40, no. 1, pp. 23-32, 2013 (Japanese).

[55] T. Sota, "Altitudinal variation in life cycles of carabid beetles: Life-cycle strategy and colonization in Alpine Zones," Arctic and Alpine Research, vol. 28, no. 4, pp. 441-447, 1996.

[56] D. J. Kotze and R. B. O'Hara, “Species decline - But why? Explanations of carabid beetle (Coleoptera, Carabidae) declines in Europe," Oecologia, vol. 135, no. 1, pp. 138-148, 2003.

[57] T. Magura, B. Tóthmérész, and T. Molnár, "Changes in carabid beetle assemblages along an urbanisation gradient in the city of Debrecen, Hungary," Landscape Ecology, vol. 19, no. 7, pp. 747759, 2004.

[58] L. Grüm, "Carabid fecundity as affected by extrinsic and intrinsic factors," Oecologia, vol. 65, no. 1, pp. 114-121, 1984.

[59] P. Brandmayr, "The reduction of metathoracic alae and of dispersal power of carabid beetles along the evolutionary pathway into the mountains," in Form and function in Zoology, G. Lanzavecchia and R. Valvassori, Eds., pp. 363-378, Mucchi, Publisher Modena, 1991.

[60] P. Brandmayr, R. Pizzolotto, and S. Scalercio, "Overview: invertebrate diversity in Europe's alpine regions," in Alpine Biodiversity in Europe, L. Nagy, G. Grabherr, C. h. Koerner, and D. B. A. Thompson, Eds., Ecological Studies, pp. 233-238, Springer, Berlin, Heidelberg, Germany, 2003.

[61] Y. Kaseno, Geology of Ishikawa-ken, Japan: with geological maps, Ishikawa Prefecture, Kanazawa, Japan, 2001, In Japanese.

[62] S. M. Schmid, B. Fügenschuh, E. Kissling, and R. Schuster, "Tectonic map and overall architecture of the Alpine orogen," Eclogae Geologicae Helvetiae, vol. 97, no. 1, pp. 93-117, 2004.

[63] T. Suttiprapan, S. Yamamoto, and H. Nakamura, "Species composition and the vertical niche breath of ground beetles (Carabidae, Brachinidae) in the Southern Japan Alps," Japanese Journal of Entomology and Zoology, vol. 17, no. 4, pp. 143-152, 2006.

[64] S. Hiramatsu, "Species composition of carabid beetles (Coleoptera, Carabidae and Brachinidae) on a riverbank of the Tedori River," Biogeography, vol. 9, no. 1, pp. 31-40, 2007.

[65] N. Fujii, "Phylogeographic importance of the mountainous region of central Honshu for Japanese alpine plants," Bunrui, vol. 1, pp. 5-14, 2008.
[66] L. Š. Jelaska, V. Dumbović, and M. Kučinić, "Carabid beetle diversity and mean individual biomass in beech forests of various ages," ZooKeys, vol. 100, pp. 393-405, 2011.

[67] Z. Elek, T. Magura, and B. Tóthmérész, "Effect of canopy closure of a young Norway spruce plantation on ground beetles," in European Carabidology 2003: Proceedings of the 11th European Carabidologists Meeting, Aarhus, G. Lovei and S. Toft, Eds., Danish Institute of Agricultural Sciences report, pp. 89-97, European Carabidology, Aarhus, Denmark, 2005.

[68] J. Rykken, D. E. Capen, and S. P. Mahabiri, "Ground beetles as indicators of land type diversity in the green mountains of Vermont," Conservation Biology, vol. 11, no. 2, pp. 522-530, 1997.

[69] S. Blake, D. I. McCracken, M. D. Eyre, A. Garside, and G. N. Foster, "The relationship between the classification of Scottish ground beetle assemblages (Coleoptera, Carabidae) and the National Vegetation Classification of British plant communities," Ecography, vol. 26, no. 5, pp. 602-616, 2003.

[70] S. Hiramatsu, "Vertical distribution of the carabid beetles at Mt. Hakusan, Ishikawa Prefecture, Japan," Bulletin of the Biogeographical Society of Japan, vol. 55, no. 1, pp. 1-6, 2000, In Japanese with English abstract.

[71] S. Hiramatsu, "Fauna and distribution of ground beetles (Coleoptera, Carabidae) in the upper subalpine and alpine zones of Mt. Hakusan," Japanese Journal of Entomology (New Series), vol. 11, no. 1, p. 12, 2008, In Japanese with English abstract.

[72] S. Hiramatsu, "The occurrence of the ground beetles (Coleoptera, Carabidae) on a snow field in the Alpine zone," Japanese Journal of Entomology (New Series), vol. 14, no. 4, pp. 281-289, 2011 (Japanese), (In Japanese with English abstract).

[73] T. Magura, B. Tóthmérész, and T. Molnár, "A species-level comparison of occurrence patterns in carabids along an urbanisation gradient," Landscape and Urban Planning, vol. 86, no. 2, pp. 134-140, 2008.

[74] A. Honek, "The effect of temperature on the activity of Carabidae (Coleoptera) in a fallow field," European Journal of Entomology, vol. 94, no. 1, pp. 97-104, 1997.

[75] X.-D. Yu, L. Lü, T.-H. Luo, and H.-Z. Zhou, "Elevational Gradient in Species Richness Pattern of Epigaeic Beetles and Underlying Mechanisms at East Slope of Balang Mountain in Southwestern China," PLoS ONE, vol. 8, no. 7, Article ID e69177, pp. 1-10, 2013.

[76] M. Laternser and M. Schneebeli, "Long-term snow climate trends of the Swiss Alps (1931-99)," International Journal of Climatology, vol. 23, no. 7, pp. 733-750, 2003.

[77] P. W. Mote, A. F. Hamlet, M. P. Clark, and D. P. Lettenmaier, "Declining mountain snowpack in western north America," Bulletin of the American Meteorological Society, vol. 86, no. 1, pp. 39-49, 2005.

[78] G. Kudo, "Monitoring of mountain ecosystems under climate change: its significance and perspectives," Global Environment, vol. 19, no. 1, pp. 3-11, 2014.

[79] H. Daimaru and M. Yasuda, "Global warming and mountain wet meadows in Japan," Chikyu Kankyo, vol. 14, no. 2, pp. 175$182,2009$.

[80] M. Yasuda, H. Daimaru, and S. Okitsu, "Detection of alpine moor vegetation change by comparison of orthonized aerophotographs at different times," Geographical Review of Japan, vol. 80, no. 13, pp. 842-856, 2007.

[81] H. Furuike, N. Shirai, and A. Yoshimoto, Vegetation geography of subalpine and alpine zone in Mt. Hakusan and its long-term changes. 2. Decrease of snow-bed vegetations in Midaga-hara 
plain in this half - century, vol. 5 of Bulletin of the Ishikawa Museum of Natural History, In Japanese, 1 edition, 2015.

[82] R. O. Weber, P. Talkner, and G. Stefanicki, "Asymmetric diurnal temperature change in the Alpine Region," Geophysical Research Letters, vol. 21, no. 8, pp. 673-676, 1994.

[83] Intergovernmental Panel on Climate Change (IPCC), "Impacts, Adaptation and Vulnerability. Contribution of Working Group II to the Fourth Assessment Report of the Intergovernmental Panel on Climate Change," in Climate Change, M. L. Parry, O. F. Canziani, J. P. Palutikof, P. J. van der Linden, and C. E. Hanson, Eds., Cambridge University Press, Cambridge, UK, 2007.

[84] P. Schoeneich and C. de Jong, "Changes in the Alpine environment. How will the Alpine environment be tomorrow and for what activities?" Journal of Alpine Research, vol. 96, no. 4, pp. 65-76, 2008. 


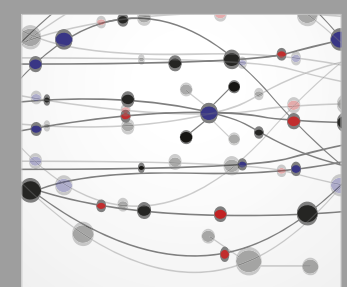

The Scientific World Journal
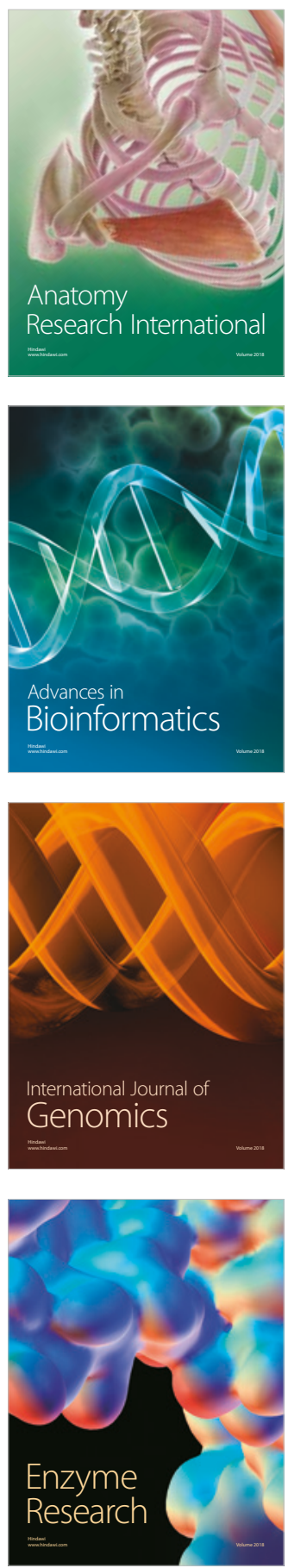
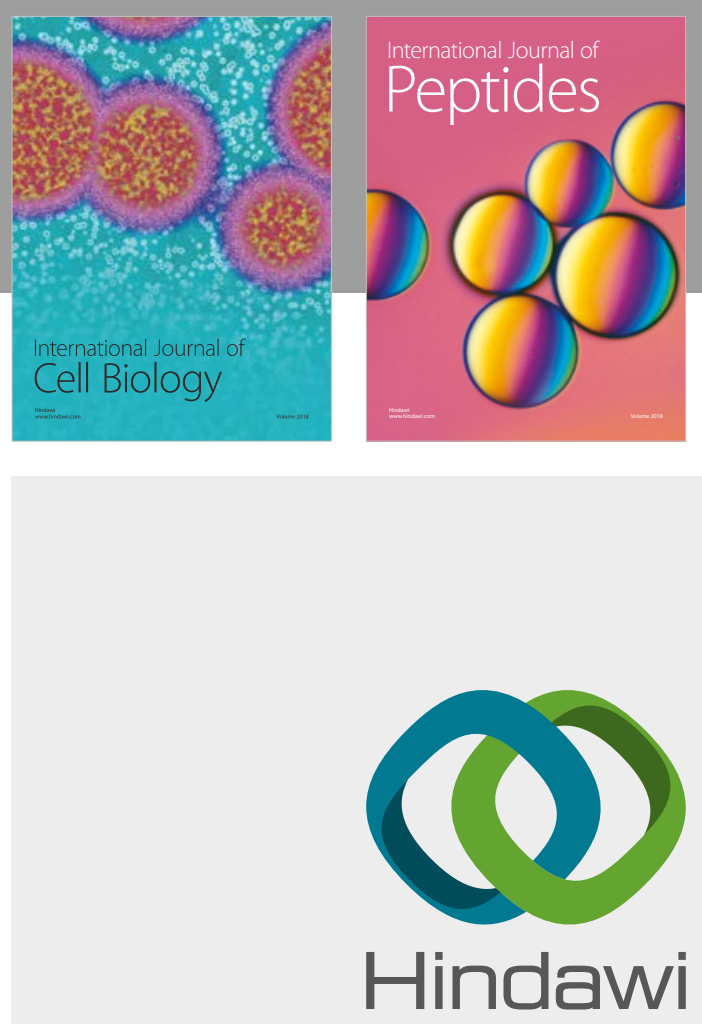

Submit your manuscripts at

www.hindawi.com
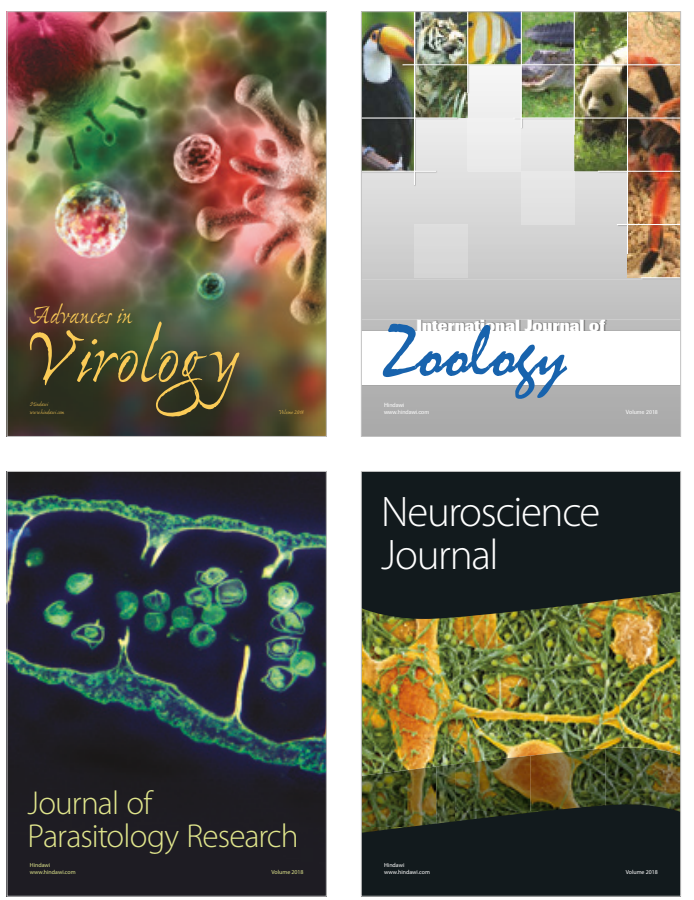
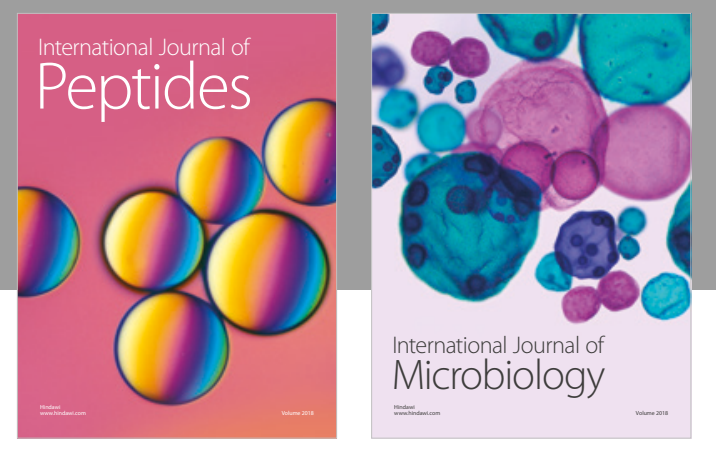

nternational Journal of Microbiology
Journal of
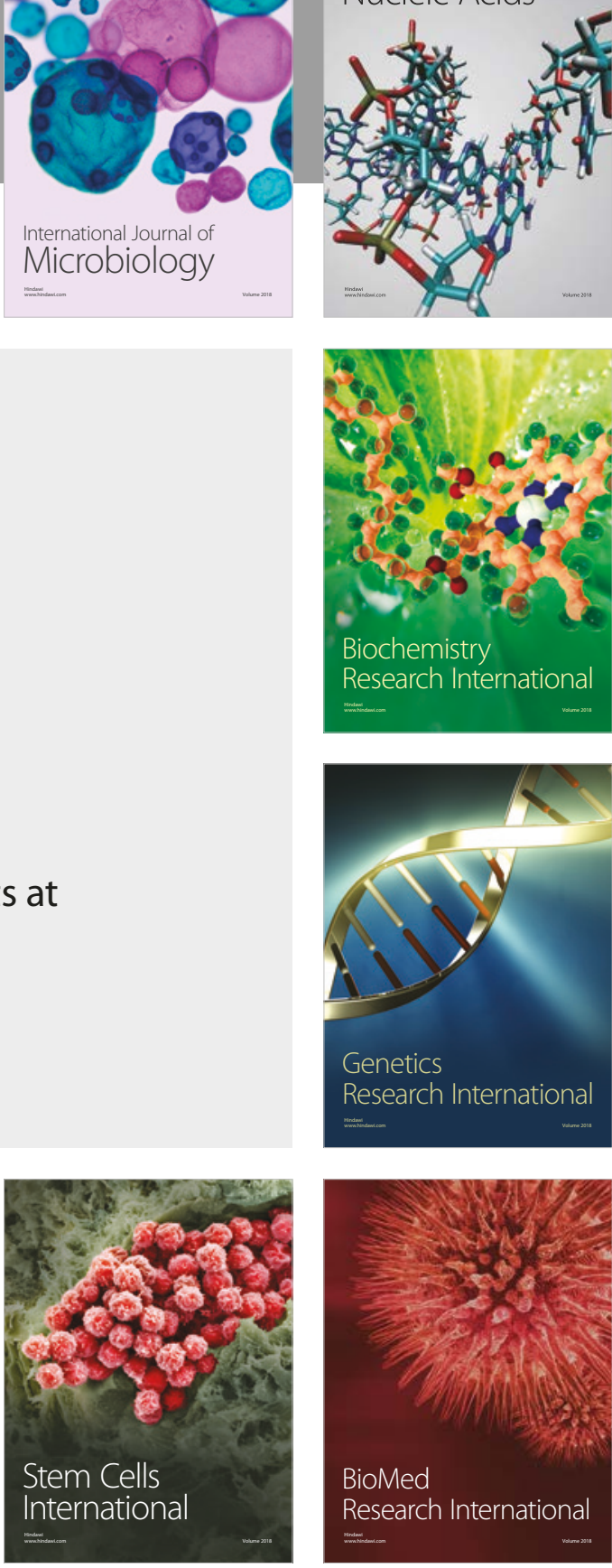
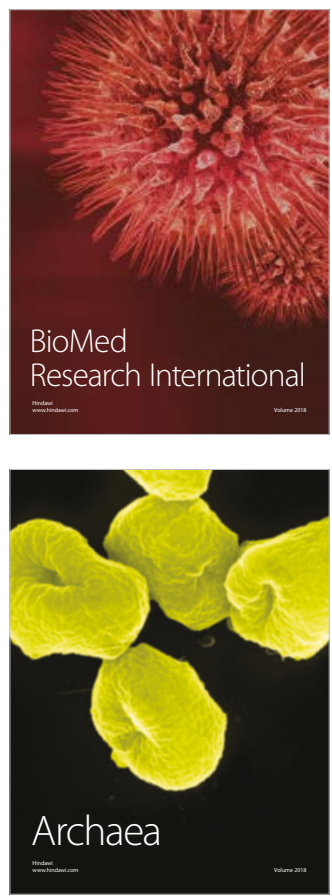